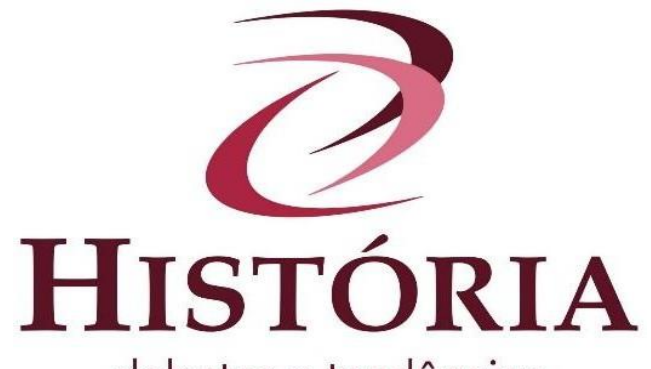

\title{
Polonidade no Brasil: papel dos atores sociais e das instituições na manutenção e/ou extinção do patrimônio cultural
}

\section{Polonity in Brazil: the role of social actors and institutions in the maintenance and / or extinction of cultural heritage}

\section{Polskość w Brazylii: rola aktorów społecznych oraz instytucji obywatelskich w kultywowaniu i/lub zanikaniu dziedzictwa kulturowego}

Schirlei Mari Freder ${ }^{\mathrm{i}}$

\begin{abstract}
Resumo: Depois de 150 anos dos grandes fluxos da imigração polonesa ao Brasil, é possível constatar as mais diferentes influências dessa etnia na cultura brasileira imbricadas em diferentes cidades e estados. O objetivo deste estudo é continuar com uma análise acerca da influência dos atores (ou agentes) sociais na manutenção e/ou extinção das diferentes instituições fundadas por poloneses e seus descendentes nas últimas décadas no Brasil. Pode-se concluir que existem diferentes motivações subjetivas que levam determinado ator social a agir a favor ou contra os elementos culturais de seu grupo étnico. Em um primeiro momento histórico, havia muita força da atuação em grupo por meio das instituições, significado que foi se alterando, especialmente após o período de nacionalização no Brasil. $\mathrm{Na}$ contemporaneidade, o que se espera é que o ator sinta-se parte de uma rede que representa a polonidade e, mesmo que ele não saiba todos os códigos culturais de sua etnia, nem queira agir de modo tão participativo, pode influenciar e colaborar para a manutenção do patrimônio cultural (material e imaterial) de várias maneiras, que incluem as redes sociais. Portanto, o nível de importância das instituições permanece, tanto para as finalidades de recreação e lazer quanto para as legítimas formas de expressão cultural da etnia polonesa.
\end{abstract}

Palavras-chave: Atores sociais. Instituições culturais. Cultura polonesa. Polonidade no Brasil.

\begin{abstract}
After 150 years of big flows of polish immigration to Brazil, we can verify the most different influences of this ethnicity in the Brazilian culture imbricated in different cities and states. The objective of this study is to continue with an analysis regarding the influence of the social actors (or agents) in the maintenance and/or extinction of the different institutions founded by polish people and their descendants in the last decades in Brazil. We could conclude that there are different subjective motivations that drove determined social actor to act in favor of or against the cultural elements of their ethnical group. In a first historical moment, the acting in group through the institutions had a lot of strength - a meaning that changed itself, especially after the period of nationalization in Brazil. In the present, what is expected is that the actor feels part of a network that represents the polonity and, even if they don't know all the cultural codes of their ethnicity, or don't want to act in
\end{abstract}


such a participative way, they can influence and collaborate to the maintenance of the cultural patrimony (material and immaterial) in many ways, including the social networks. Therefore, the level of importance of the institutions remains, both to the recreational and leisure purposes and to the legitimate ways of cultural expression of the polish ethnicity. Keywords: Social Actors. Cultural Institutions. Polish Culture. Polonity in Brazil.

Streszczenie: Po 150 lat wielkich polskich imigracji do Brazylii możemy jeszcze zauważać najróżniejsze wpływy tej mniejszości narodowej, zamieszkałej w różnych miastach oraz Stanach, na brazylijską kulturę. Cel niniejszego artykułu jest kontynuacją analizy wpływu działaczy społecznych na przetrwanie oraz zaprzestanie różnych instytucji założonych przez Polaków albo ich potomków w ciągu ostatnich dekad. Możemy wnioskować, że istnieją różne subjektywne motywacje, które sprawiają, że pewien działacz wspiera albo przeciwdziała elementom kulturowym swojej grupy etnicznej. W pierwszym momencie historycznym praca $\mathrm{w}$ grupach przy pomocy instytucji była ważna, ale sytuacja się zmieniła zwłaszcza po tzw. okresie „nacjonalizacji” w Brazylii. We współczesności oczekuje się od działacza społecznego czucia przynależności do sieci reprezentującej polskości a nawet, gdyby nie znał wszystkich kodów kulturowych swojej grupy etnicznej, albo nawet, gdyby nie chciał uczestniczyć aktywnie, może wpływać na utrzymanie dziedzictwa kulturowego (materialnego oraz niematerialnego) w różnych sposobach, w tym media społecznościowe. Zatem poziom istotności instytucji trwa, nie tylko w celu ludycznych, ale też jako forma wyrazu kulturowego dla polonii.

Słowa kluczowe: Działacze społeczni. Instytucje kulturalne. Kultura polska. Polskość w Brazylii.

\section{Introdução}

Entre os diferentes estudos e áreas temáticas que envolvem a polonidade no Brasil, investigar as instituições é um grande desafio, tanto pela ausência de catalogação de dados quanto pela dificuldade em acessá-los, para os casos das instituições ainda ativas. Alguns desses aspectos foram explorados no estudo de Freder e Trindade (2016), em uma tentativa de iniciar uma aproximação com o tema com esse recorte de análise. Existem diferentes estudos sobre a polonidade, tais como os ligados ao idioma, escolas, arquitetura, culinária, entre outros, por isso, abordar os agentes sociais e as instituições torna-se algo diferenciado.

Ao falarmos de instituições, as que primeiro se destacaram foram as igrejas e as escolas, inicialmente comunitárias, já que a estrutura governamental nos primeiros anos da imigração ainda não supria tal necessidade, e isso ocorreu com diferentes grupos étnicos. Desse modo, o que se constata é que as instituições serviam aos interesses dos patrícios poloneses, tendo como objetivo principal uma "lógica da institucionalização étnica, comemoração de datas cívicas polonesas, apresentações de teatro, música, festejos relacionados com a cultura do país de origem, além de atividades esportivas e recreativas" (FREDER; TRINDADE, 2016, p. 101), que, aos poucos se integravam às demandas locais, em um processo de aculturação e integração com a realidade apresentada em cada cidade e 
estado brasileiro.

Mais tarde, a partir dos anos de 1938, as instituições foram obrigadas a se manterem fechadas e/ou tiveram restrições em dar sequência a alguns tipos de atividades coletivas, tendo em vista o processo de nacionalização em todo o território nacional, momento em que houve diferentes ações, dentre elas a proibição de outras expressões culturais que não fossem vinculadas à cultura brasileira, incluindo o idioma, fato que culminou com o fechamento de escolas e instituições estrangeiras, bem como processos isolados de represálias aos imigrantes das mais diferentes etnias.

[...] a campanha de nacionalização eliminou possibilidades reais de manutenção da identidade de grupos de imigrantes estabelecidos no Brasil, ao proibir nas instituições o idioma estrangeiro. Desta forma pretendia-se impor valores nacionais aos brasileiros, em detrimento do sentimento de pertencimento ao seu país de origem. O governo federal impôs uma legislação educacional que previa a transformação da sociedade brasileira. Dentro de uma realidade formada por uma diversidade étnica propunha-se uma padronização social construída nos moldes dos projetos federais, forjando uma identidade brasileira (SEYFERTH, 1990, p. 90 apud VIECHNIESKI, 2020, p. 35).

Diante desse fato, o que se percebeu em alguns aspectos foi que a nacionalização trouxe severas consequências em relação à fragilização do vínculo cultural das etnias, e o que se viu foram movimentos de uma espécie de "esfriamento" cultural coletivo, que se estendeu nas décadas seguintes. A cultura foi mantida apenas no âmbito familiar, muitas vezes em segredo. Nesse período, algumas entidades conseguiram se manter ativas, mesmo sem as atividades, mas a grande maioria sucumbiu. Das que sobreviveram, podemos constatar que há um novo ânimo que surge por volta dos anos de 1970, em um movimento ascendente desde então. Para os poloneses e descendentes, uma justificativa para o resgate do vínculo com os elementos da polonidade se deu pelo fato de que um conterrâneo, Karol Józef Wojtyła - Papa João Paulo II, foi nomeado ao papado em 1978. Com isso, surgem novos movimentos para expressar livremente a polonidade. Tal constatação se deu em razão de percepção baseada em diálogos e relatos orais (não sistematizados) em diferentes espaços socioculturais, dos quais a autora participou mais ativamente a partir de 2011.

A partir dos anos de 2010, o que se vê é um movimento um pouco mais fortalecido, em uma espécie de resgate da polonidade no Brasil, que inclui o restabelecimento de relações com a Polônia que instituiu novos acordos para reaproximação dos descendentes pelo mundo, incluindo o Brasil. Desse modo, o governo polonês implementa uma série de políticas de apoio e incentivo que incluem: bolsas de estudo ou descontos atrativos para cursos de verão para o estudo do idioma e cultura polonesa; bolsas para estudos e pesquisas 
universitárias; e, mais recentemente, no ano de 2019, a concessão da Karta Polaka ${ }^{\text {ii }}$ (Carteira de Polonês), que certamente trará interações futuras.

Diante do exposto, o que se pretende neste estudo exploratório é, com base em revisão de literatura, bem como em relatos de observação de campo, avançar na compreensão do papel social exercido por lideranças políticas, culturais e/ou religiosas na criação, manutenção e/ou extinção de instituições polonesas e/ou polono-brasileiras ao longo das últimas décadas no Brasil.

\section{O contexto do surgimento das sociedades e instituições}

Desde os primórdios da organização das cidades e sociedades, é sabido da importância e da influência dos mais diversos tipos de instituições que eram organizadas para servir aos seus grupos de interesse nas mais diferentes áreas, tais como cultural, saúde, social, comercial, educacional, entre outras, e com os poloneses não foi diferente.

Ao falarmos de instituições, no contexto da imigração de grupos étnicos ao Brasil, as que primeiro se destacaram foram as igrejas e as escolas, inicialmente comunitárias, já que a estrutura governamental ainda não supria tal necessidade, e isso ocorreu com diferentes grupos étnicos:

As experiências das escolas comunitárias de imigrantes integram a história da educação no Brasil, constituindo um processo escolar étnico, característico de alemães, italianos, poloneses e japoneses. Esses grupos se estabeleceram em áreas rurais, formando núcleos populacionais marcados pela sua identidade étnicocultural, organizando suas próprias escolas com uma forte conotação confessional cristã, exceção feita aos japoneses (VIECHNIESKI, 2020, p. 151).

$\mathrm{Na}$ perspectiva da imigração polonesa ao Brasil, encontramos relatos dessas instituições, tanto das que existiram na Polônia quanto das que surgiram no Brasil. Das que existiam na Polônia, uma delas, a Sociedade Comercial e Geográfica de Lwów, fundada em 1894 em Lwów, na Polônia ocupada, tinha como propósito, além de comercializar e exportar produtos poloneses, editar um jornal que continha um "Caderno Suplementar" "dedicado aos problemas da emigração, que ostenta interessantes relatos, que ajudaram a compreender o fenômeno imigratório" (RODYCZ, 2011, p. 68). Dentre os objetivos dessa sociedade, estava o de apoiar os emigrantes no desenvolvimento de atividades econômicas e comerciais em seus locais de destino, entretanto, ao contrário de outros emissários ou agentes que angariavam famílias para emigrarem e omitiam a verdadeira situação social em que se encontravam os imigrantes no Brasil, a Sociedade relatava "as péssimas condições 
vivenciadas pelos emigrados, a que era dada ampla divulgação” (RODYCZ, 2011, p. 69). Das instituições que surgiram no Brasil, a primeira delas é a Sociedade Tadeusz Kościuszko, fundada em 15 de junho de 1890, em Curitiba, Paraná. Nos anos seguintes, o que se viu foram diversas instituições sendo criadas em cidades brasileiras.

Vemos então que, antes mesmo da febre imigratória para o Brasil, já havia instituições na Polônia que concediam apoio aos seus patrícios com interesse de tentar nova vida em outro país. Portanto, podemos entender que essa forma de se organizar em sociedades e instituições representativas veio com os imigrantes.

\footnotetext{
Desde o início, os imigrantes perceberam também a importância de viver em colônias e próximos aos seus compatriotas, a quem poderiam se socorrer e ao mesmo tempo desenvolverem-se juntos, criando uma nova sociedade. A vontade de vencer fez com que os colonos se organizassem logo em comunidades, que giravam em torno da igreja, sociedade e escola. (GARDOLINSKI, 1976 apud VIECHNIESKI, 2020, p. 109).
}

À medida que os primeiros imigrantes chegavam ao Brasil, se organizavam comunitariamente e priorizavam a construção de capelas, igrejas e escolas, conforme explorado em Freder e Trindade (2016). Os registros das primeiras instituições com cunho social, cultural, recreativo e esportivo deu-se a partir dos anos de 1890. Estas, em sua maioria estabelecidas na região Sul do Brasil, imbricavam suas funções e atividades dentre as demandas locais em seus municípios de origem, servindo às mais diferentes causas.

\footnotetext{
Estas instituições representariam o desejo da maioria, com objetivos comuns que iam desde a religião com a construção de uma igreja e o estabelecimento de um padre na Colônia, a educação e o que se refere ao sistema de ensino escolar para seus filhos, a organização de cooperativas agrícolas com busca por melhores preços, sementes e maquinários, o lazer com a organização de atividades culturais e especialmente um ambiente de convivência e manutenção de suas tradições (VIECHNIESKI, 2020, p. 29).
}

As instituições passavam a desempenhar um importante papel em cada localidade e, de fato, foram criadas inúmeras delas em curto período de tempo. As questões que surgem são: Por que eram fundadas tantas instituições, próximas umas às outras e, na maioria das vezes, com as mesmas finalidades? Pela dificuldade de locomoção seria mais cômodo ter uma delas mais próximo àquele grupo de famílias?

Nos importantes relatos de Głuchowski (2005) que constam no estudo de Freder e Trindade (2016), conseguimos iniciar uma compreensão acerca dessa questão: 
[...] apesar da criação dessas várias sociedades, tratava-se de esforços sem nenhuma coordenação, esparsos; cada colônia fundava por conta própria uma associação, mantendo pouco ou nenhum contato com as outras organizações. De modo geral essas sociedades eram muito fracas, tinham de lutar sobretudo com a falta de apoio dos colonos, com a falta de pessoas capacitadas e de meios, e nos centros maiores, principalmente Curitiba, com as intrigas e animosidades pessoais dos líderes, que muitas vezes prejudicavam as sociedades que mal começavam a funcionar (FREDER; TRINDADE, 2016, p. 101).

O número de instituições era expressivo, conforme relato entusiasmado de Głuchowski (2005):

[...] cinquenta anos após o momento em que os primeiros colonos poloneses puseram o seu pé em solo brasileiro, o nosso patrimônio nesse campo já é bastante considerável. As associações e sociedades crescem dia a dia em número de sócios e em significado, e é nesse setor que finalmente começa a se desenrolar toda a nossa vida étnica e social (GŁUCHOWSKI, 2005, p. 139).

Embora houvesse um grande número de instituições, a maioria sucumbia logo em seguida da fundação, dentre as razões, estão a falta de recursos para sua manutenção e os conflitos entre seus membros, especialmente entre as lideranças responsáveis pelo protagonismo da instituição e da causa que esta representava. Em alguns casos, acontecia o contrário, ou seja, surgia o protagonismo pessoal, deixando a instituição em segundo plano. Esses conflitos refletiam na própria comunidade, que certamente esperava que a missão da instituição se cumprisse.

\footnotetext{
Głuchowski não deixa de mencionar as disputas internas entre os poloneses. Conflitos entre lideranças por razões religiosas, políticas, pessoais, entre outras, geravam, segundo o autor, a desorganização e não permitiam o desenvolvimento da comunidade polonesa, impedindo a criação de associações mais amplas que congregassem diferentes instituições e a própria continuidade das mais antigas. Em todos os grupos sociais (como os étnicos) existem divisões, referentes a variadas formulações, ainda mais quando remetem à constituição identitária grupal, que envolve posicionamentos e capacidade de enunciação e ativação de determinadas situações em relação a outras, ou seja, o potencial de "representação" que alguns porta-vozes têm nas disputas simbólicas (FREDER; TRINDADE, 2016, p. 105).
}

Outra constatação importante nas pesquisas é que, desde as propagandas da época da colonização, para divulgar a venda de terras, por exemplo, nos anos de 1921, na região de Guarapuava, Paraná, havia a informação de permissão e apoio, tanto para a construção de igreja e escola quanto para a construção de uma sociedade, conforme vemos nos estudos de Viechnieski (2020, p. 54-55): 
[...] propagandas de venda das terras na Colônia em diversos jornais, informando a localização, o valor, as condições da negociação, as características da terra, das perspectivas de desenvolvimento, vantagens, entre outros, como podemos ver: [...] Terra em Guarapuava - Loteamento da fazenda Amola Faca - 18.000 alqueires - além de Guarapuava, junto à estrada para Foz do Iguaçu. Terra a escolher ao preço de $60 \$ 000$ a $70 \$ 000$ por alqueire. Título definitivo assegurado. Em Amola Faca será fundada uma vila e reservada uma área para escola, igreja e casa para uma sociedade. Os primeiros colonos já ali adquiriram suas terras. Para pedir informações, dirigir-se ao endereço: WLADYSLAW RADECKI GUARAPUAVA - PARANÁ (JORNAL LUD, n. 27, 1921, p. 3 apud VIECHNIESKI, 2020, p. 54-55).

É, portanto, inegável a importância social das sociedades e instituições, conforme relatos em jornais de época, apresentados nos estudos de Viechnieski (2020):

\begin{abstract}
Uma edição do Jornal Świt, datada de 1921, ano em que se iniciam os trabalhos de colonização da Colônia Amola Faca, traz um relato feito pelo Cônsul da República da Polônia, Sr. Głuchowski, de uma viagem pelas colônias polonesas. O conteúdo nos dá mostra de sua distância em relação às demais, que também são detalhadas, bem como do caminho a percorrer: [...] Há pouco tempo, encontrase em Guarapuava também o agrimensor Sr. Ladislau Radecki. É um pequeno grupo, apenas 30 famílias, mas que possui uma Sociedade Polonesa, com uma biblioteca e uma sala de leitura. [...] A impressão geral de toda Guarapuava foi muito simpática. A região é bonita e, de acordo com a opinião dos criadores locais, nos campos poderia ser desenvolvida a criação de ovelhas para a lã, que na Polônia é tão necessária. A colônia polonesa não é muito numerosa, mas ativa. Subscreveram alguns milhares para o Banco Polonês, e a Sociedade Polonesa agregou-se à organização Cultura (JORNAL ŚWIT, n. 14, 1921, p. 1, apud VIECHNIESKI, 2020, p. 118-119; 121).
\end{abstract}

Neste outro trecho, há uma publicação em nota de jornal de 1927, também dos estudos de Viechnieski (2020):

\begin{abstract}
À noite no prédio da Sociedade Educativa e Cultual, realizou-se um baile, no qual, aos acordes dessa mesma orquestra de Prudentópolis (que dessa vez de nada pôde ser censurada), as pessoas se divertiram até o amanhecer. No dia seguinte, isto é, no domingo, após a celebração da santa missa, os padres, bem como os convidados, voltaram às suas casas. Ficou apenas o vazio, e somente o sino lembra todos os dias à obrigação do trabalho. [...] Henrique Krygier, professor de Virmond (JORNAL LUD, n. 73, 1927, p. 2-3 apud VIECHNIESKI, 2020, p. 129).
\end{abstract}

Cabe mencionar o caso de uma instituição na cidade de Virmond, no Paraná, a Sociedade Agrícola Instrutiva de Virmond. Fundada nos anos de 1923, a instituição funcionou aproximadamente até os anos de 2005, teve seu nome alterado diversas vezes ao longo das décadas, tanto em razão da alteração de sócios, de estatuto e de fusão de outras 
instituições quanto por força da legislação brasileira. Após a paralisação das atividades, a edificação se deteriorou, desse modo, a prefeitura local desapropriou o patrimônio, alegando risco de queda da edificação (ZAPAHOWSKI, 2020). A seguir, a constatação acerca das atividades que ocorriam nas instituições da cidade:

\footnotetext{
Quando o Clube Sociedade Instrutiva Agrícola de Virmond foi criado, serviu de espaço de lazer e cultura a toda comunidade, então os bailes passaram a ser realizados no local. Mais tarde outros dois clubes foram construídos, então quando não havia baile em um, havia no outro (PSZDZIMRISKI, 1998, p. 47 apud VIECHNIESKI, 2020, p. 79).
}

A ocorrência da desapropriação da edificação histórica pode nos trazer diferentes indagações, tais como: Não existe mais interesse da comunidade polonesa local na manutenção da edificação e da polonidade? Existem líderes ou agentes que poderiam batalhar pela manutenção do patrimônio que representa a identidade polonesa na cidade? Ou, as políticas culturais no Brasil não atendem tais demandas?

Esse não é um fato isolado, são diversas "perdas" patrimoniais materiais, de edificações, nas mais diferentes cidades brasileiras nas últimas décadas. Edificações que outrora representavam fortemente os poloneses e seus interesses, mas que foram perdendo as funções inicialmente estabelecidas, bem como sofrendo a ação causada pelo afastamento de líderes e demais interessados em se envolver com a polonidade. As razões reais cabem em uma investigação mais minuciosa, que, inclusive, são de interesse da autora.

Outra questão que perpassa os aspectos de perdas patrimoniais, agora voltada para o patrimônio imaterial, que é algo sutil, mas que poderá ser medido ao longo dos anos, tratase da saída dos padres da congregação da Sociedade de Cristo de diversas comunidades em municípios do Sul do Brasil. Em sua maioria, são padres poloneses que desempenham um importante papel religioso e também social, sendo agentes ativos da cultura polonesa para essas comunidades. Isso se dá por meio das expressões culturais que se apresentam na manutenção do idioma, com as conversações, missas e orações em polonês, bem como por meio das celebrações religiosas ligadas diretamente à cultura polonesa, tais como a benção dos alimentos na Páscoa (Święconka) e a vigília de Natal com o pão ázimo (Opłatek).

Por fim, a sociedade e as instituições necessitam das pessoas para existirem e, por isso, compreender de que modo os agentes sociais se movimentam é algo que instiga diferentes questionamentos, que serão explorados no próximo item deste estudo. 


\title{
O papel dos agentes e líderes das instituições
}

A respeito do papel dos líderes e dos agentes sociais, sem dúvida, ambos têm um nível de importância e influência nas instituições. Essa constatação perpassa por diferentes trabalhos que relatam tanto o processo de imigração quanto os primeiros anos dos imigrantes no Brasil. São obras de Głuchowski (2005, [1927]); Anais da Comunidade Brasileiro-Polonesa nos anos de 1970; Fryder Rockenbach (1996); Polanczyk (2010); Malikoski (2018); Krieger (2019).

Para abordarmos o papel dos agentes e líderes, podemos escolher diferentes correntes teóricas, dentre elas as que discutem as relações de poder que se instalam nas estruturas sociais, presentes nas obras de Michel Foucault, Pierre Bourdieu e Max Weber, ou seguir por outra linha de pensamento mais voltada para as questões vinculadas ao campo cultural, sendo esta a escolha neste artigo. Este estudo perpassa pela etnicidade de Fredrik Barth a partir da obra de Philippe Poutignat e Jocelyne Streiff-Fenart, pela antropologia cultural de Roque de Barros Laraia e também pela teoria ator-rede (actor network-theory) de Bruno Latour, John Law e Michel Callon.

Iniciando pelos aspectos da etnicidade, entendemos que essa abordagem contribui para compreendermos o modo como cada membro de um determinado grupo étnico se comporta dentro de sua comunidade.

\begin{abstract}
Sob o ponto de vista da etnicidade, alguns estudos apontam que os próprios atores sociais envolvidos nos processos culturais, podem manter e/ou simplesmente eliminar elementos de uma cultura. Sim, cada um de nós, que se identifica como ator social em um processo cultural tem algumas responsabilidades no momento de transmitir e manter uma cultura. Vejam que mesmo com as mudanças geográficas, nossos antepassados procuraram adaptar o que foi possível para que conseguissem manter vivas algumas tradições e códigos culturais que representam o povo polonês (FREDER; FREDER, 2017, p. 116).
\end{abstract}

Considerando os aspectos do comportamento intracomunidade, cada ator ou agente social escolhe como quer se posicionar e, desse modo, contribuir para a manutenção ou extinção de determinados elementos de sua cultura. Esses elementos podem ser compreendidos como símbolos ou códigos culturais vinculados ao patrimônio material ou imaterial daquele grupo, sendo que sua manutenção depende da ação das pessoas que compõem aquele tecido social em determinado recorte temporal. 
sejam postas de lado por uma ou mais gerações. Em alguns casos um dado patrimônio edificado pode ser mantido, porém negado por uma geração, fazendo com que este equipamento seja uma "cicatriz" no tecido social daquele grupo étnico (FREDER; FREDER, 2017, p. 119).

Além da decisão de colaborar, ou não, há também aspectos importantes a serem considerados que estão relacionados às diferentes formas de expressar uma cultura. Para o caso que estamos analisando, a cultura polonesa, esta se expressa de diferentes formas no Brasil, com a culinária, o canto, o folclore e as danças, o idioma, o artesanato, a religiosidade, etc. O que contatamos em campo é que os atores sociais não conseguem participar ativamente de todos os tipos de expressão de sua cultura, e isso é afirmado por Laraia (2007, p. 80): “A participação do indivíduo em sua cultura é sempre limitada; nenhuma pessoa é capaz de participar de todos os elementos de sua cultura". Desse modo, o que se espera é que mesmo que determinado ator não participe daquela expressão cultural, que possa então compreender que esta importa para outros atores de seu grupo étnico e assim consiga, de fato, colaborar na manutenção da cultura.

\footnotetext{
Mas, qualquer que seja a sociedade, não existe a possibilidade de um indivíduo dominar todos os aspectos de sua cultura. Isto porque, como afirmou Marion Levy Jr., "nenhum sistema de socialização é idealmente perfeito, em nenhuma sociedade são todos os indivíduos igualmente bem socializados, e ninguém é perfeitamente socializado. Um indivíduo não pode ser igualmente familiarizado com todos os aspectos de sua sociedade; pelo contrário, ele pode permanecer completamente ignorante a respeito de alguns aspectos". [...] O importante, porém, é que deve existir um mínimo de participação do indivíduo na pauta de conhecimento da cultura a fim de permitir a sua articulação com os demais membros da sociedade (LARAIA, 2007, p. 82).
}

Ao agregarmos as observações empíricas com a teoria apresentada neste estudo, podemos confirmar que o papel do ator social na manutenção de sua cultura independe de seu grau de escolaridade e de sua classe social, mas depende, sim, de seu interesse, de seu grau de influência e de sua capacidade de articulação intra e extracomunidade.

Há casos de desentendimentos entre sócios ou associados de uma instituição que levaram um determinado líder a fazer incidência contra outro membro, a ponto de causar uma fusão no quadro societário, mudando os rumos daquela entidade em determinada localidade. Certamente situações parecidas ocorreram em diversos municípios, levando as entidades a encerrarem suas atividades, conforme historicamente lemos em obras da etnia polonesa.

Essa perspectiva também é abordada por Laraia (2007), quando fala dos aspectos de 
nosso padrão cultural que influenciam nosso comportamento, que muitas vezes ferem aspectos intracomunidade, como as ofensas pessoais quando não se concorda com o comportamento de um ou de outro ator.

\begin{abstract}
A nossa herança cultural, desenvolvida através de inúmeras gerações, sempre nos condicionou a reagir depreciativamente em relação ao comportamento daqueles que agem fora dos padrões aceitos pela maioria da comunidade. Por isso, discriminamos o comportamento desviante (LARAIA, 2007, p. 67-68).
\end{abstract}

Cabe destacar que aqui não estamos nos referindo à intervenção extracomunidade de outros grupos étnicos que, eventualmente, não se interessem pelas expressões culturais polonesas e tentam destruí-la. Mas, sim, falamos de atores dentro do grupo étnico polonês, que, por alguma razão, escolhem não se envolver e/ou causar conflitos, não colaborando na manutenção de algum elemento de sua expressão cultural, seja material ou imaterial.

Por fim, trazemos agora outro aspecto teórico que certamente contribuirá para refletirmos acerca do papel dos atores com base em outra perspectiva. Se as cidades mudam e o idioma se altera com o passar do tempo, consequentemente as sociedades também se alteram. Compreender esse aspecto da impermanência pode justificar o comportamento dos atores em relação à preservação ou não de determinado bem de sua cultura.

\footnotetext{
Compreendemos que a construção da memória e do patrimônio está relacionada aos modos de vida vivenciados pelos grupos sociais não homogêneos, plurais e mutáveis e, assim, verificamos esta construção como um instrumento tanto de transformação quanto de inclusão, reelaborando, deste modo, as práticas sociais no presente (SAMPAIO; LOUREIRO; LIMA, 2017, p. 9).
}

Com base nesse novo recorte de análise, cabe apontar a teoria ator-rede (actor network-theory), que também considera aspectos como os vinculados "às relações, fluxos e mediações" (SAMPAIO; LOUREIRO; LIMA, 2017). Sem dúvida, vivemos novos fluxos e mediações em todas as relações sociais do mundo contemporâneo, que também contempla as redes sociais, e no âmbito étnico essa questão também é percebida.

Se considerarmos o grupo étnico polonês enquanto rede, podemos imaginar uma grande teia de atores, instituições e elementos da cultura (materiais e imateriais) que interagem entre si. Eis o grande desafio, fazer com que esses atores se sintam parte dessa grande teia e, em momentos de aglomeração em eventos festivos, por exemplo, é quando acontece a conexão, ou o nó, dessa grande rede. Passado o evento ou encontro, os atores, seus grupos e instituições retornam para suas rotinas e, mesmo assim, continuam fazendo 
parte da rede.

[...] uma rede não se reduz a um ator singular, mas, é composta de elementos humanos e não humanos conectados, com características heterogêneas. Neste contexto, memória e patrimônio são abordados sob o ponto de vista da inclusão, a partir da compreensão de interação, advinda do interior das relações sociais que considera a multiplicidade e a diversidade de fatores envolvidos como produtoras de sentidos e significados diversos na perspectiva da 'rede'. [...] Sujeitos e objetos exercem influências significativas uns sobre os outros, na forma de agir e, assim, humanos e não humanos sofrem alterações no tempo e espaço, perpetuando, desta forma, a troca de influências. $\mathrm{O}$ foco das construções e relações sociais centradas somente no elemento "humano" ou "social" é fruto das demais materialidades que constituem a "realidade" (SAMPAIO; LOUREIRO; LIMA, 2017, p. 1).

Concluímos a análise desse item acerca dos atores sociais compreendendo que, mesmo que o ator não domine todas as expressões culturais de seu grupo, mesmo que ele não esteja em posições privilegiadas de poder, mesmo que ele não detenha recursos físicos ou financeiros, se ele se colocar em posição de membro de uma rede "atuando" em favor da cultura, ele terá condições de ser visto. Dentre esses aspectos subjetivos, a forma como esse ator escolhe se posicionar frente ao grupo deve ser acolhida pelo coletivo, sem julgamentos.

Existem, portanto, diferentes formas de atuação do ator social no mundo contemporâneo, seja por meio da associação a uma instituição, seja a participação em grupos das mídias sociais, e até mesmo sendo porta-voz da polonidade em seu ambiente de trabalho ou no seu meio de convivência. Todas essas escolhas ou não escolhas fazem do sujeito um ator que compõe a rede.

\section{Considerações finais}

O tema não se esgota nesse assunto e há muito a explorar, afinal, essas abordagens teóricas apontam para o ineditismo de observar a etnia polonesa com base nesses vieses. Considerando todos os aspectos apontados neste estudo, vemos que a força dos indivíduos vinha da forma como se agrupavam e criavam as instituições, sem dúvida, algo fundamental nas primeiras décadas após a imigração. Com o passar do tempo, os imigrantes já naturalizados com o país, e também sofrendo as consequências do processo de nacionalização, acabam alterando seu comportamento nas décadas seguintes, fato que influenciou no esfriamento cultural coletivo, mesmo que individualmente e em família estivesse mantido.

Mais recentemente, o que se vê é uma reconexão com a polonidade graças a uma série de fenômenos, dentre eles o novo cenário econômico vivido pela Polônia, que motivou a criação de novas políticas para se reaproximar de seus descendentes pelo mundo. Essas 
políticas oferecem atrativos que, de certo modo, contribuem para que os atores se sintam pertencentes à polonidade, mesmo que de um modo diferente, se compararmos com décadas atrás. A diferença é que a maioria dos descendentes não teve contato com o idioma e, para acessarem determinados projetos, necessitam antes estudar o idioma, com isso, em alguns anos veremos boas respostas em relação a essa reconexão.

Sem dúvida, o sentido de pertencimento ao vínculo com a Polônia contemporânea é diferente de décadas atrás, quando, na maioria dos casos, os imigrantes e depois seus descendentes sequer tiveram oportunidade de visitar o país de origem, tanto pelas dificuldades e recursos no Brasil quanto por todo contexto histórico que a Polônia viveu nos últimos 100 anos. Por isso, o pertencimento étnico se alterou nas últimas décadas.

Por fim, acreditamos que há um novo desafio para a comunidade polono-brasileira no que tange à preservação de instituições, patrimônio, legado e memória, que é se sentirem parte de algo que é comum a todos, se enxergando em uma grande rede, bem como fortalecer laços intergeracionais para repasse das memórias, espaços subjetivos em que possam se influenciar mutuamente em prol da polonidade. Só assim, haverá a salvaguarda do patrimônio e da memória, tendo como guardiãs as instituições socioculturais. Portanto, o nível de importância das instituições permanece, tanto para as finalidades de recreação e lazer quanto para as legítimas formas de expressão cultural da etnia polonesa.

\section{Referências}

FREDER, Schirlei Mari; FREDER, Remy. Atores sociais e a polonidade: preocupações com a manutenção da cultura. Polonicus: Revista de reflexão Brasil-Polônia, Curitiba, Missão Católica Polonesa no Brasil, ano 8, n. 14, jan./jun. 2017. Disponível em <https://www.polonicus.com.br/arquivos/pdf-pt-2017-05-28\%2023-25-58.pdf > Acesso em: 27 jul. 2020.

FREDER, Schirlei Mari; TRINDADE, Rhuan Targino Zaleski. Organizações polonobrasileiras: origens, constituição jurídica e planos de sucessão. Polonicus: Revista de reflexão Brasil-Polônia, Curitiba, Missão Católica Polonesa no Brasil, ano 7, n. 13, jul./dez. 2016. Disponível em: <https://www.polonicus.com.br/arquivos/pdf-pt-2017-0110\%2013-58-51.pdf>. Acesso em: 27 jul. 2020.

LARAIA, Roque de Barros. Cultura: um conceito antropológico. 21. ed. Rio de Janeiro: Jorge Zahar, 2007.

GŁUCHOWSKI, Kazimierz. Os poloneses no Brasil - Subsídios para o problema da colonização polonesa no Brasil. Porto Alegre: Rodycz \& Ordakowski Editores, 2005.

REPÚBLICA DA POLÔNIA. Karta Polaka. Disponível em: 
<https://www.gov.pl/web/brasil/karta-polaka>. Acesso em: 10 ago. 2020.

RODYCZ, Wilson Carlos. Os imigrantes poloneses da Colônia Lucena - Itaiópolis: se um marreco pisar no gelo ele quebra. Porto Alegre: Rodycz \& Ordakowski Editores, 2011.

SAMPAIO, Débora Adriano Sampaio; LOUREIRO, José Mauro Matheus Loureiro;

LIMA, Izabel França de Lima. Memória, patrimônio e inclusão social: um olhar a partir da teoria ator-rede. Revista Thema, v. 14, n. 4, 2017.

VIECHNIESKI, Selma Antonia Pszdzimirski. Tensões na construção identitária polonesa: o caso da Colônia Amola-Faca/Virmond (PR). [recurso eletrônico]. 2. ed. Porto Alegre: Editora Fi, 2020. 219 p.

ZAPAHOWSKI, Geraldo. Entrevista via WhatsApp em agosto de 2020.

Submetido em: $14 / 08 / 2020$

Aprovado em: 05/09/2020

Publicado: 23/09/2020

\footnotetext{
' Doutora e Mestre em Gestão Urbana (PUCPR); Professora convidada em Programas de Pós-Graduação (ISAE; PUCPR; Uninter).

ii A Karta Polaka (Carteira de Polonês) é um documento que confirma o pertencimento à Nação Polonesa. [...] A Carteira de Polonês não significa a aquisição da cidadania polonesa, nem é um documento que permite cruzar a fronteira ou se estabelecer na República da Polônia (REPÚBLICA DA POLÔNIA, 2019).
} 